PAPER

\title{
Gamma knife stereotactic radiosurgery for unilateral acoustic neuromas
}

\author{
J G Rowe, M W R Radatz, L Walton, A Hampshire, S Seaman, A A Kemeny
}

J Neurol Neurosurg Psychiatry 2003;74:1536-1542

See end of article for authors' affiliations

.....................

Correspondence to:

Dr J Rowe, Department of Stereotactic Radiosurgery, Royal Hallamshire Hospital, Glossop Road, Sheffield S10 2JF, UK: jeremy.rowe@sth.nhs.uk

Received 12 June 2002

In revised form

5 February 2003

Accepted

15 February 2002

Objective: To evaluate the clinical results achievable using current techniques of gamma knife stereotactic radiosurgery to treat sporadic unilateral acoustic neuromas.

Methods: A retrospective review of 234 consecutive patients treated for unilateral acoustic neuromas between 1996 and 1999, with a mean (SD) follow up of 35 (16) months. Tumour control was assessed with serial radiological imaging and by the need for surgical intervention. Hearing preservation was assessed using Gardner-Robertson grades. Details of complications including cranial neuropathies and non-specific vestibulo-cochlear symptoms are included.

Results: A tumour control rate in excess of $92 \%$ was achieved, with only $3 \%$ of patients undergoing surgery after radiosurgery. Results were less good for larger tumours, but control rates of $75 \%$ were achieved for 35-45 mm diameter lesions. Of patients with discernible hearing, Gardner-Robertson grades were unchanged in $75 \%$. Facial nerve function was adversely affected in $4.5 \%$, but fewer than $1 \%$ of patients had persistent weakness. Trigeminal symptoms improved in 3\%, but developed in $5 \%$ of patients, being persistent in less than $1.5 \%$. Transient non-specific vestibulo-cochlear symptoms were reported by $13 \%$ of patients.

Conclusions: Tumour control rates, while difficult to define, are comparable after radiosurgery with those experienced after surgery. The complications and morbidity after radiosurgery are far less frequent than those encountered after surgery. This, combined with its minimally invasive nature, may make radiosurgery increasingly the treatment of choice for small and medium sized acoustic neuromas.

S tereotactic radiosurgery, whether delivered by a gamma knife or a linear accelerator, is increasingly recognised as an alternative treatment to conventional microsurgery in the management of acoustic neuroma. ${ }^{1}$ The use of radiosurgery for acoustic neuromas has been described in several series of more than 100 patients. ${ }^{2-9}$ In an attempt to provide a reasonable length of follow up and sufficient patient numbers, some studies have included patients from the early 1990s and combined results for unilateral tumours with those secondary to type 2 neurofibromatosis (NF2). In interpreting these data we were aware of how much our radiosurgical practice had changed in the last decade; how these changes might not be apparent to individuals not working in radiosurgical units; and how they could have a marked effect on clinical results.

These changes in radiosurgery have reflected both technical advances and refinements in patient selection and referral. Magnetic resonance imaging (MRI) has improved targeting. More powerful computer software and hardware (GammaPlan, Elekta AB, Sweden) allows more complex plans using more isocentres to be formulated, increasing the accuracy and conformality of treatments. The magnitude of this change (illustrated in fig 1 ) is reflected in the fact that during 1992-93 we used an average of 1.8 isocentres to cover an acoustic neuroma, and this increased to 5.6 in the period covered by this study.

There has also been an evolving appreciation of the dose of radiation required to achieve tumour control. Early series used doses to the periphery of the tumour of 25 and later $17.5 \mathrm{~Gy} .{ }^{10}$ Since then there has been a progressive reduction in dose which, at least in our NF2 material, has significantly reduced the incidence of cranial nerve deficits while not compromising rates of tumour control. ${ }^{11}$ These observations have led us to our current practice of generally prescribing doses in the range of 13-15 Gy.
In addition to these technical changes, the case mix of patients referred has also changed. Initially, only tumours that were unfavourable surgical targets were referred. Hence the average size of acoustic neuromas was larger, more tumours were post-surgical recurrences, and there was a large proportion of patients with NF2. In our early series (1986-89), $72 \%$ of the acoustic neuromas treated were secondary to NF2; this fell to $44 \%$ in $1992-93$, and to $12 \%$ in 1998-99. The results of surgery for NF2 acoustic neuromas are poorer than those achievable for the sporadic unilateral condition, ${ }^{12}$ and the same is true for radiosurgery. For this reason we are reporting our radiosurgical experience treating NF2 tumours separately, ${ }^{11}$ and have concentrated here on the results that can be expected applying current gamma knife radiosurgical techniques to sporadic unilateral acoustic neuromas.

\section{METHODS}

Patient details

Between January 1996 and December 1999, 234 patients with sporadic unilateral acoustic neuromas were treated in Sheffield with stereotactic radiosurgery, the medical records being traced in 232 of these cases. There were 129 women (55\%) and 105 men $(45 \%)$ in the group, the mean age at treatment being 56 (13) years (range 23 to 85 ). Fifty nine patients $(25 \%)$ had previously undergone surgery for the acoustic neuroma, in eight cases on multiple occasions, and were being treated for residual or recurrent disease. Of the group, $108(47 \%)$ were considered to be totally deaf (Gardner-Robertson grade $\mathrm{V}^{13}$ ) and only 50 (22\%) were deemed to have useful hearing (Gardner-Robertson grades III). Deafness was significantly more common in the patients who had undergone previous surgery, as were the presence of facial nerve palsies and trigeminal neuropathies (all $p<0.001$, see table 1). 


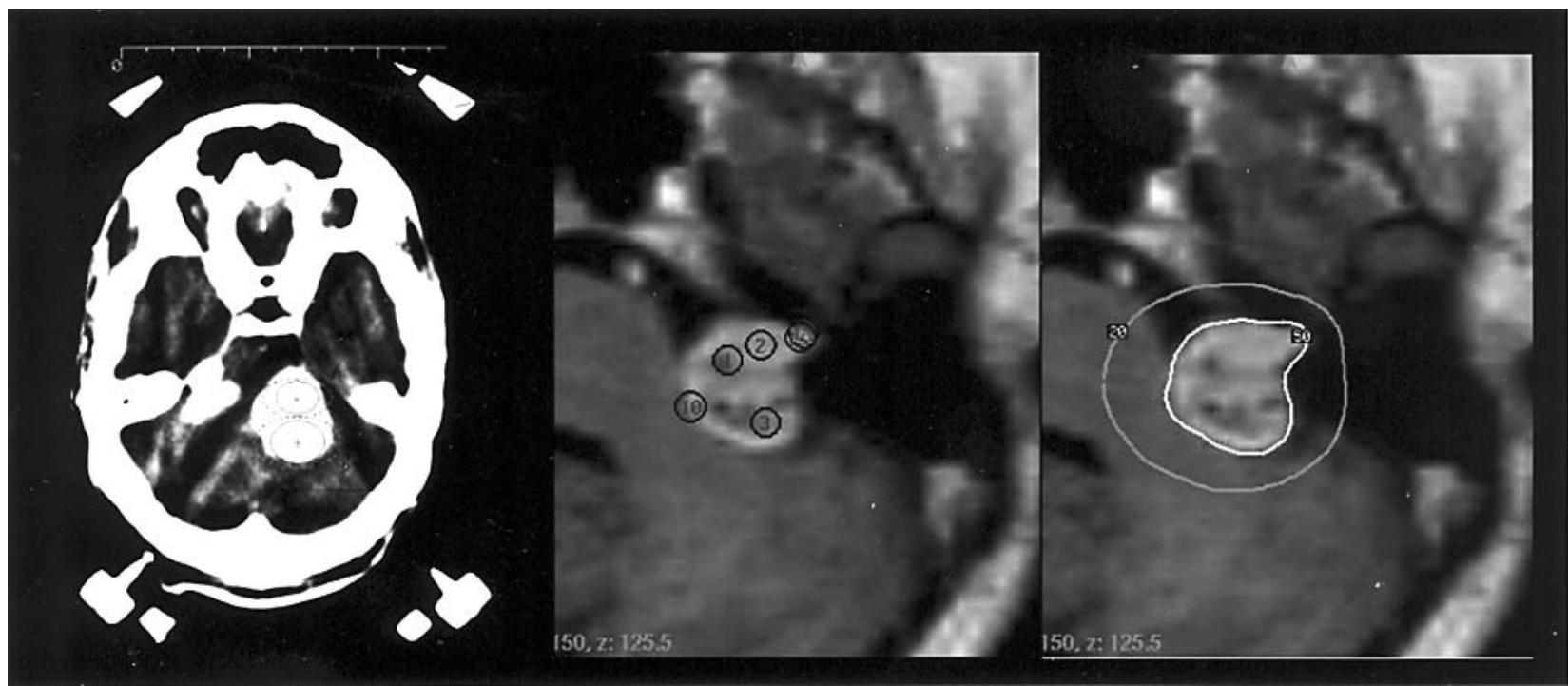

Figure 1 Illustration of the change in patient selection and treatment planning. On the left is a planning computed tomographic scan from 1992, in which two isocentres are being used to treat a large acoustic neuroma in a patient with type 2 neurofibromatosis. The centre picture is a patient in the series reported here, treatment of a unilateral acoustic neuroma being planned with several isocentres to generate the highly conformal plan on the right.

Seventy nine of the patients (34\%) had documented growth of their acoustic neuromas on serial imaging before radiosurgery was undertaken. Fifteen patients were referred as a planned postoperative strategy, to treat a significant tumour remnant. Twenty eight patients harboured large tumours approaching $3 \mathrm{~cm}$ in diameter. Progressive symptomatology (deafness in 120 cases, trigeminal neuropathy in 19 , and balance problems in 14) was also a factor in patients seeking active treatment.

The tumours treated in 1996 were significantly larger than those treated in subsequent years $(\mathrm{p}<0.05)$. Included in table 2 are follow up details, the median follow up for the whole patient group being 34 months, with a mean value of 35 (16) months.

\section{Gamma knife radiosurgery}

The use of the Leksell gamma knife (Elekta, Sweden) for the treatment of acoustic neuromas has been well described. ${ }^{4}{ }^{14}$ In brief, the procedure consists of fixing the Leksell stereotactic frame to the patient's head and acquiring radiological images with the stereotactic localiser in place. These images are then processed using GammaPlan (Elekta $\mathrm{AB}$, Sweden). Currently our planning is largely based on

Table 1 Patient disability before stereotactic radiosurgery: damage to the fifth, seventh, and eighth cranial nerves was significantly more common $(p<0.001)$ in those who had previously undergone open surgery

\begin{tabular}{llll}
\hline & Overall & $\begin{array}{l}\text { Primary } \\
\text { STRS }\end{array}$ & $\begin{array}{l}\text { Previous } \\
\text { surgery }\end{array}$ \\
\hline Patient numbers & 232 & 173 & 59 \\
Hearing & & & \\
Grade I-II & 50 & 50 & 0 \\
Grade III-IV & 74 & 73 & 1 \\
$\quad$ Grade V & 108 & 50 & 58 \\
Facial palsy & 53 & 9 & 44 \\
Trigeminal neuropathy & 64 & 35 & 29 \\
\hline
\end{tabular}

Patient morbidity before treatment; included in the nine patients with "facial palsy" who had not previously undergone surgery are five individuals with hemi-facial spasm but no weakness. STRS, stereotactic radiosurgery. gadolinium enhanced $T_{1}$ weighted volumetric MRI scans. We have on occasion used MRI-computed tomography (CT) image fusion techniques. Typically, the $50 \%$ isodose contour is matched to the margin of the tumour, and is used to prescribe a peripheral dose between 13 and 15 Gy. In this series the median peripheral dose was $15 \mathrm{~Gy}$, with a mean value of 14.6 ( 1.3 ) Gy. The median number of isocentres used was 6 , mean $5.6(2.4)$. The plan is also used to check the radiation exposure of the adjacent tissues.

Having constructed a suitable plan, the patient is positioned on the gamma knife treatment couch, and the stereotactic frame is attached to the collimator helmet. The treatment itself is silent and painless. The treatment is covered with dexamethasone (4 mg four times daily, started the night before radiosurgery and stopped the morning after) to minimise the perceived risk of headache or nausea.

\section{Clinical assessment and follow up}

Assessment is based upon clinical, radiological, and audiometric examinations carried out annually. Many of the examinations were done locally in the referring hospitals according to our protocol. When follow up information was incomplete, missing information was sought from the neurosurgeons, neuro-otologists, and the primary care physicians involved with the individual's care. Overall, 20\% of the patients were followed up in Sheffield, 63\% by local neurosurgical services, and $15 \%$ by specialist neuro-otological services. When follow up was done by the referring unit, review of the radiological images was sought to obtain precise measurements.

Tumour control was assessed both by considering whether surgery to resect the acoustic neuroma was undertaken, and by considering the size of the lesion on serial imaging. Because patients were scanned with different imaging techniques using different scanners in different centres, the radiological assessment used in this paper is primarily qualitative, based on neuroradiologists' opinions comparing the most recent scan with that used for planning the treatment.

Hearing function was graded using the Gardner-Robertson system ${ }^{13}$ based on the patient's description of his hearing and the audiometric information. Facial weakness was graded 
Table 2 Patient and treatment details divided by the year in which treatment was undertaken

\begin{tabular}{|c|c|c|c|c|c|c|c|c|c|c|c|c|}
\hline \multirow[b]{2}{*}{ Year } & \multirow{2}{*}{$\begin{array}{l}\text { Number } \\
\text { of patients }\end{array}$} & \multirow{2}{*}{$\begin{array}{l}\text { Tumour volume } \\
\left(\mathrm{mm}^{3}\right) \text { (mean (SD)) }\end{array}$} & \multirow{2}{*}{$\begin{array}{l}\text { Previous } \\
\text { surgery }\end{array}$} & \multicolumn{3}{|c|}{ Marginal dose (Gy) } & \multicolumn{3}{|c|}{ Number of isocentres } & \multicolumn{3}{|c|}{ Follow up (months) } \\
\hline & & & & Median & Mean & (SD) & Median & Mean & (SD) & Median & Mean & (SD) \\
\hline 1996 & 47 & $5370(5230)$ & $23 \%$ & 15 & 14.6 & $(1.5)$ & 6 & 5.7 & (2.1) & 59 & 53 & (17) \\
\hline 1997 & 37 & 2650 (3200) & $35 \%$ & 15 & 14.6 & (1.5) & 6 & 5.6 & (2.3) & 47 & 47 & (8) \\
\hline 1998 & 59 & $3350(4300)$ & $32 \%$ & 15 & 14.8 & (1.1) & 5 & 5.3 & (2.2) & 36 & 35 & (9) \\
\hline 1999 & 91 & 3530 (3930) & $16 \%$ & 15 & 14.4 & (1.3) & 6 & 5.7 & (2.6) & 24 & 23 & (7) \\
\hline
\end{tabular}

Tumour volumes were significantly larger in 1996 than in subsequent years $(p<0.05)$, but in other respects treatment variables altered little during this period. Patient details by year.

using the House-Brackmann scale. ${ }^{15}$ Included in the figures for facial nerve palsy (but not graded) are individuals with no weakness but who have hemifacial spasm. Trigeminal neuropathy was considered to be present whenever there was a subjective description of numbness or sensory change, regardless of whether there were objective physical signs.

Follow up is expressed in terms of surviving tumours and excludes patients undergoing tumour resection. Tumour resection, and the time when it occurs, is considered separately as a distinct end point, reflecting the fact that surgery may occur soon after radiosurgery, but follow up may continue thereafter. All values are expressed as mean (SD), with additional median values being quoted. Comparisons between subgroups use $\chi^{2}$ and $t$ tests as appropriate. Tumour resection rates were calculated both as a simple percentage and using Kaplan-Meier plots. Additionally, a regression analysis was undertaken examining the effects of tumour volume, prescribed dose, documented growth before treatment, and previous surgery on the tumour response to radiosurgery.

\section{RESULTS}

\section{Tumour control}

Of the 232 patients, seven (3\%) underwent surgery a mean of 16 (9) months (range 1 to 28) after radiosurgery. The KaplanMeier plot (fig 2) gave a similar value of $96 \%$ of patients not requiring surgery after 28 months (when the last tumour in this series was resected). This reflects the fact that the mean patient follow up of 35 (16) months was longer than the interval between radiosurgery and salvage surgical procedures, there being few censored observations in the calculation.

Of the seven patients who underwent surgery, four had tumours which at the time of radiosurgery measured at least $3 \mathrm{~cm}$, with two being larger than $4 \mathrm{~cm}$. Of the two $4 \mathrm{~cm}$ tumours (both postsurgical recurrences), one was a partially cystic lesion in an elderly patient who continued to deteriorate clinically, and had surgical intervention a month after the radiosurgery. The other $4 \mathrm{~cm}$ tumour was rapidly growing (approximately $1 \mathrm{~cm} /$ year) before radiosurgery, and as growth continued, surgery was undertaken after a further period of 15 months. Of the remaining five patients, one had a $2 \mathrm{~cm}$ tumour (recurrent after previous surgery) with a growth rate that was not altered by the radiosurgery; her second surgical procedure was carried out two years after the radiosurgery. In the other four cases, the decisions to intervene surgically were taken because of patients' symptoms, only one of these tumours having uncontrolled growth.

The only other surgical interventions were three patients who developed hydrocephalus and required shunting a mean of 16 (20) months after the radiosurgery. Nine patients in this series had required shunts before radiosurgery.

There have been concerns about tumour control in five other individuals. One underwent surgery in 1993, sustaining a grade 5 facial palsy. Subsequently she developed a tumour recurrence with documented growth that was treated with radiosurgery in 1997 . The tumour unfortunately continued to grow over the following two years. The patient refused further surgery, and so was treated for a second time with radiosurgery, 14 months after which the tumour appears controlled. Two further patients have had 5-7 mm of tumour growth over two to three years, and decisions about their future management are pending. One elderly patient, who is a poor surgical candidate, is also awaiting a decision on further management, having developed a cyst contiguous with her acoustic neuroma. One patient was considered to have some tumour growth two years after radiosurgery (undertaken in 1996) but was subsequently lost to follow up, there being no record of any further therapeutic intervention.

Adequate imaging data to assess tumour control were available for 212 of the 234 patients. Fifteen (7\%) showed evidence of an increase in the tumour size compared with the planning films. Ten of these cases have already been described above, and five represent modest increases in tumour volume which have subsequently stabilised in two patients and are being observed in three. One patient had tumour shrinkage followed by subsequent enlargement, although the residual mass is still smaller than it was before treatment. If all the patients detailed above are considered as treatment failures, the tumour control rate is in excess of $92 \%$. Considering this combined control rate based on imaging and surgical intervention, patients receiving radiosurgery for recurrences after previous surgery fared significantly worse (with a tumour control rate of 86\%) when compared with those receiving radiosurgery as primary treatment (control rate $94 \%, \mathrm{p}<0.05$ ). This result has to be interpreted with some caution as the numbers of patients failing radiosurgery remains small.

Of the 212 patients with adequate imaging data, tumours were unchanged in size in $115(54 \%)$ and decreased (as illustrated in fig 3) in 82 cases (38\%). On multivariate regression analysis, increasing the radiation dose prescribed to the tumour margin was significantly $(\mathrm{p}<0.05)$ associated

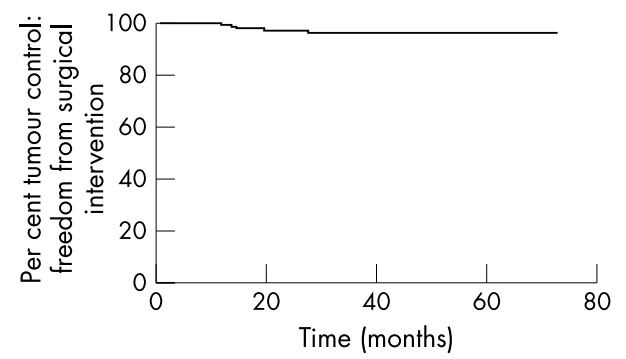

Figure 2 A Kaplan-Meier plot illustrating tumour control defined by the freedom from surgical intervention. The nearly horizontal line reflects the fact that surgery was undertaken rarely (in only seven of the 234 cases), and when it was done that it took place relatively soon (on average 16 (9) months) after the radiosurgery. When this time interval is compared with the average follow up of 35 (16) months for the whole patient group, it is appreciated that censored observations have relatively little effect on this line. 
with tumour shrinkage (whereas other factors, tumour volume, tumour growth documented radiologically before treatment, and previous surgery, were not; see table 3 ). The odds ratio per 1 Gy increase in marginal dose was 1.31, with a 95\% confidence interval between 1.02 and 1.68.

\section{Hearing preservation}

Of the 227 patients assessed, 108 (47\%) were completely deaf before radiosurgery, 49 (22\%) had useful Gardner-Robertson grade I-II hearing, and 70 (31\%) had non-useful grade III-IV hearing (table 4). Of the 119 patients with discernible hearing, the Gardner-Robertson grade ascribed before treatment was unchanged after radiosurgery in $75 \%$. This proportion was the same for patients with useful and nonuseful hearing, although there was a tendency for patients with good hearing to retain some hearing function, while those with poor hearing went completely deaf. The effect of previous surgery on hearing preservation after subsequent radiosurgery could not be assessed, as these patients were almost universally deaf before the radiosurgical treatment.

\section{Facial nerve function}

Of 225 patients with complete data, 213 experienced no change in facial nerve function after radiosurgery, and in two function improved. (In one case hemifacial spasm resolved: in the other a postoperative facial palsy improved, although it may have done so anyway (table 4.$)$ ) In 10 patients $(4.5 \%$ ) facial nerve function was adversely affected, but this persisted in only two cases (less than 1\%). Persistent facial weakness (that is, persisting beyond the duration of the study) occurred in one patient undergoing radiosurgery as primary treatment with a previously intact facial nerve, a grade 3 palsy developing; and in one patient who felt that her grade 4 palsy, a complication of previous surgery, was worse after radiosurgery. A transient weakness developed in four further patients with previously normal function and in one patient who already had a grade 2 palsy. None of these patients had undergone previous surgery. Hemifacial spasm developed as a new symptom in one patient, and was exacerbated in two other individuals; however, in all three this resolved with time. There was no difference in facial nerve complication rates between patients primarily treated
Table 3 Results of a multivariate regression analysis examining factors associated with tumour shrinkage after radiosurgery

\begin{tabular}{|c|c|c|c|}
\hline & Significance & $95 \% \mathrm{Cl}$ & Odds ratio \\
\hline $\begin{array}{l}\text { Marginal dose } \\
\text { (Gy) }\end{array}$ & 0.03 & 1.02 to 1.68 & 1.31 \\
\hline Previous surgery & 0.13 & 0.84 to 3.92 & 1.82 \\
\hline $\begin{array}{l}\text { Documented } \\
\text { growth before } \\
\text { radiosurgery }\end{array}$ & 0.14 & 0.84 to 3.20 & 1.64 \\
\hline $\begin{array}{l}\text { Tumour volume } \\
\left(\mathrm{cm}^{3}\right)\end{array}$ & 0.59 & 0.95 to 1.10 & 1.02 \\
\hline
\end{tabular}

The only significant finding $(p=0.03)$ was that increasing the marginal dose was more likely to result in tumour shrinkage. The odds of shrinkage appear higher when the patient has not had previous surgery, and when there is growth documented with serial imaging before the radiosurgery, although these factors did not reach statistical significance. Tumour volume did not appear to be related to the likelihood of tumour shrinkage.

$\mathrm{Cl}$, confidence interval.

with radiosurgery and those who had undergone previous surgery. Patients with facial nerve palsies (or hemifacial spasm) who had not undergone previous surgery (that is, the nerve was damaged or irritated by the acoustic neuroma itself) were significantly more at risk of radiosurgery exacerbating these symptoms $(\mathrm{p}<0.001)$.

\section{Trigeminal nerve function}

Trigeminal function was unchanged in 207 of 225 patients, and improved after radiosurgery in a further seven (table 4). Seven patients developed new trigeminal symptoms and four reported an exacerbation of pre-existing ones. Of these 11 patients, symptoms resolved in eight, were persistent in two, and continued up to and were exacerbated by subsequent surgery in one. Overall, with radiosurgery, trigeminal symptoms improved in 3\% but developed and persisted in $1.5 \%$, a further $4 \%$ of patients having some transient disturbance of function. Previous surgery or pre-existing neuropathy were not statistically associated with an additional risk of developing trigeminal symptoms.

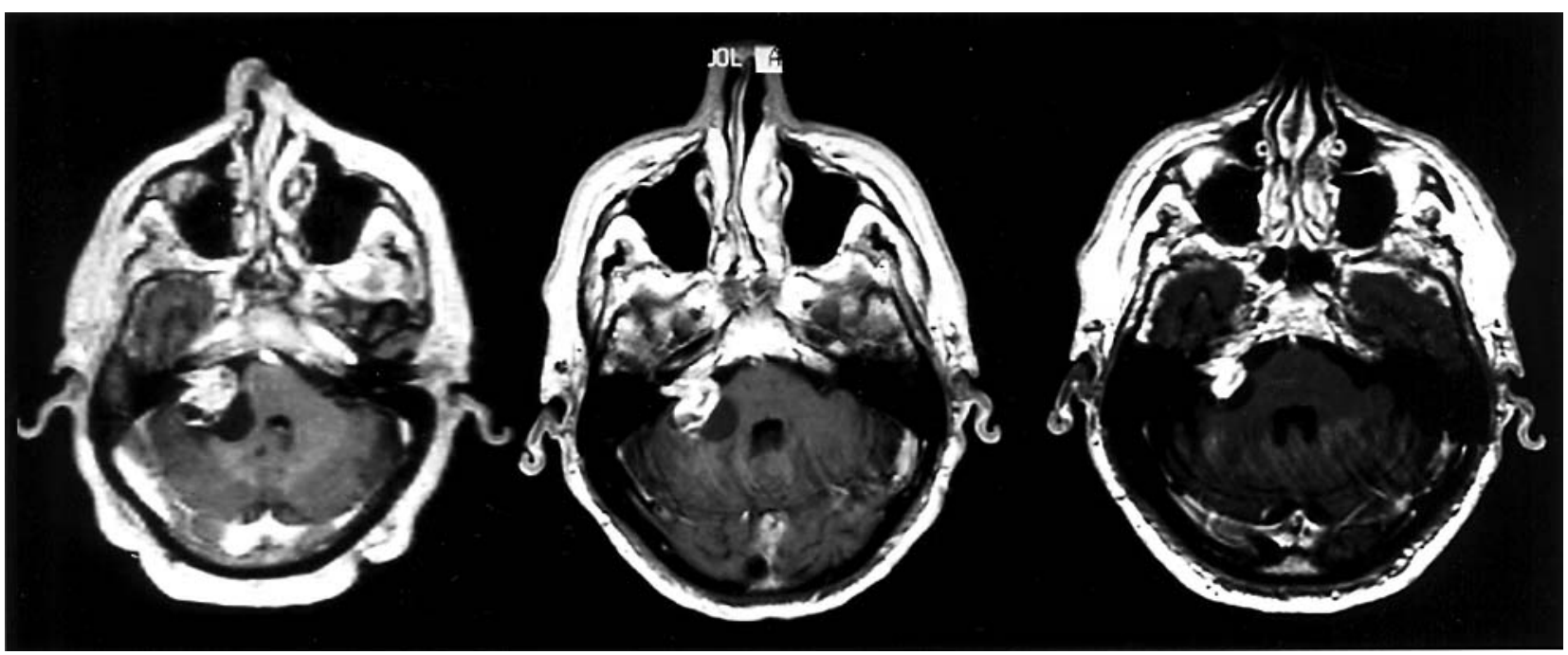

Figure 3 Illustration of an individual patient's response to treatment. The magnetic resonance image on the left was acquired at the time of radiosurgery, while the centre and right images show progressive shrinkage after two and four years. In this series, tumour shrinkage was seen in $38 \%$ of patients, and no change in tumour size in 54\%, overall a radiologically defined tumour control rate in excess of $92 \%$ being achieved. Tumour shrinkage was significantly related to the radiation dose prescribed to the tumour margin $(p<0.05)$. 
Table 4 Hearing grades use the Gardner-Robertson scale, and were preserved in $75 \%$ of patients with measurable hearing

\begin{tabular}{|c|c|c|c|c|c|}
\hline \multicolumn{2}{|c|}{ Before radiosurgery } & \multicolumn{4}{|c|}{ Hearing function after radiosurgery } \\
\hline Grade & $\begin{array}{l}\text { Number of } \\
\text { patients }\end{array}$ & \multicolumn{2}{|l|}{ Hearing preserved } & Grade decreased & Totally deaf \\
\hline \multirow{4}{*}{$\begin{array}{l}\text { I-II } \\
\text { III-IV } \\
\mathrm{V}\end{array}$} & 49 & \multirow{3}{*}{$\begin{array}{l}37(76 \%) \\
52(74 \%)\end{array}$} & \multirow{3}{*}{\multicolumn{2}{|c|}{$\begin{array}{l}11 \\
8\end{array}$}} & 1 \\
\hline & 70 & & & & 10 \\
\hline & 108 & & & & 108 \\
\hline & & \multicolumn{4}{|c|}{ Facial nerve function after radiosurgery } \\
\hline \multicolumn{2}{|c|}{ Before radiosurgery } & Unchanged & Improved & Temporary deficit & Persisting paresis \\
\hline \multirow{3}{*}{$\begin{array}{l}\text { Overall } \\
\text { Pre-existing } \\
\text { palsy without } \\
\text { surgery }\end{array}$} & 225 & 213 & 2 & 8 & $2(<1 \%)$ \\
\hline & 8 & 4 & 1 & 3 & \\
\hline & & \multicolumn{4}{|c|}{ Trigeminal nerve function after radiosurgery } \\
\hline \multicolumn{2}{|c|}{ Before radiosurgery } & Unchanged & Improved & Temporary deficit & Persisting deficit \\
\hline Overall & 225 & 207 & 7 & 8 & 3 \\
\hline
\end{tabular}

Fewer than $1 \%$ of patients suffered a persisting deterioration in facial nerve function as a result of radiosurgery. Patients with the rare condition of facial nerve symptoms directly attributable to the acoustic neuroma (as opposed to the common circumstance when they resulted from previous surgery) were significantly at risk of further deterioration after radiosurgery $(\mathrm{p}<0.001)$. Persisting trigeminal symptoms occurred in less than $1.5 \%$ of patients. Previous surgery did not increase the risk of radiosurgery causing further cranial nerve damage.

\section{Other symptoms}

Non-specific vestibulo-cochlear symptoms, earache or a "fullness in the ear", dizziness, nausea, and tinnitus are difficult to quantify and may be presenting features of the acoustic neuroma. An exacerbation of these symptoms was, however, reported by 28 patients (13\%), typically developing a minimum of four months after treatment and resolving spontaneously.

\section{DISCUSSION}

Radiosurgery has evolved in the last decade, both technologically and in terms of patient referral and selection. The results reported here are a tumour control rate of at least $92 \%$, with only $3 \%$ of patients undergoing acoustic neuroma surgery, combined with a $75 \%$ hearing preservation rate, and a risk of persisting facial and trigeminal neuropathies each of $1-1.5 \%$. It is possible that careful patient selection may improve these figures further.

These results are broadly similar to those reported by other radiosurgery groups (table 5 ), although there are differences both in complication rates and tumour control rates. There may in part be technical reasons for this, in that the early work in the Charlottesville study ${ }^{6}$ (which features the lowest hearing preservation rate), and $89 \%$ of the cases in the Tokyo study $^{8}$ (with relatively high facial and trigeminal nerve complications) both used CT localisation. Included in table 5 are the results of the only large linear accelerator radiosurgery series. ${ }^{9}$ Of note, while it too has relatively high rates of cranial neuropathy, the treatment period studied involved a dose reduction from 22.5 to $10 \mathrm{~Gy}$, the authors concluding that this was the most important factor in reducing the complications associated with acoustic neuroma radiosurgery. As noted above, this is very much in accord with our own observations based on our NF2 material. ${ }^{13}$ It was this appreciation of how much radiosurgery had evolved which prompted us to limit this study to the results achieved with current techniques and protocols.

In addition to the technical advances, part of the variability in the tumour control rates quoted in table 4 may reflect problems in defining this outcome measure. Perhaps the simplest measure is defined by the rate at which surgical intervention is required after radiosurgery. This has the advantages that surgery is a well defined end point, and that it is what patients generally want to know-they are, after all, undergoing radiosurgery to avoid it. Problems with this approach, however, include the fact that while surgery may be a clearly defined end point, the decision to perform it may not. Surgery was undertaken in four of the seven cases without apparent review by, or discussion with, our service. While it is now impossible to judge the appropriateness of these decisions, in three of these cases it could certainly be debated. We believe that the clinical message is that surgery should only be undertaken after discussion with the radiosurgical unit, and it should not be done for non-specific vestibulo-cochlear symptoms (earache, dizziness, tinnitus, and so on), as these are generally self limiting and while they are quite common after radiosurgery ( $13 \%$ in this series), they are even more common after surgery. ${ }^{16}$

Radiological control rates are less straightforward to define. Importantly a tumour which is treated radiosurgically and then increases in size before its growth stops would be regarded radiologically as a failure. If, however, growth stops and surgery is avoided, the patient might regard it as a success. In view of this, we would regard our figure of a $92 \%$ tumour control rate as a deliberately pessimistic estimate of what radiosurgery can offer. In assessing the efficacy of radiosurgery, given the normally slow growth rate of acoustic neuromas, the length of patient follow up is of obvious concern. This series may be criticised for its length of follow up (35 (16) months), but this is to some extent inevitable in reporting the results which are now being achieved with current techniques. Interestingly when surgery is done, it happens relatively soon (mean 16 (9) months) after radiosurgery, and looking at the 47 patients treated in 1996 (who have a mean follow up of 53 (17) months) there is no evidence of a late relapse rate, this being reflected in the Kaplan-Meier plot (fig 2).

In advising patients, shrinkage of the acoustic neuroma after radiosurgery appears to be a good indicator of long term growth control. In only one of 82 patients with tumour shrinkage was there subsequently any concern about regrowth. Regression analysis revealed that the dose prescribed to the tumour margin was the only identified factor associated with tumour shrinkage. Historically the trend has 
Table 5 Clinical results of recently published large series of acoustic neuromas treated with either gamma knife or linear accelerator (Linac) radiosurgery

\begin{tabular}{|c|c|c|c|c|c|c|c|c|c|c|}
\hline Centre [ref] & Unit & $\begin{array}{l}\text { Number } \\
\text { of patients }\end{array}$ & $\begin{array}{l}\text { Period of } \\
\text { study }\end{array}$ & $\begin{array}{l}\text { Follow up } \\
\text { (months) }\end{array}$ & $\begin{array}{l}\text { Tumour } \\
\text { volume } \\
\left(\mathrm{cm}^{3}\right)\end{array}$ & $\begin{array}{l}\text { Peripheral } \\
\text { dose }\end{array}$ & $\begin{array}{l}\text { Tumour } \\
\text { control }\end{array}$ & $\begin{array}{l}\text { Persisting } \\
\text { facial paresis }\end{array}$ & $\begin{array}{l}\text { Persisting } \\
\text { trigeminal } \\
\text { symptoms }\end{array}$ & $\begin{array}{l}\text { Hearing } \\
\text { preservation }\end{array}$ \\
\hline Charlottesville $^{6}$ & GK & 153 & 1989-99 & 51 & 2.7 & $13.2 \mathrm{~Gy}$ & $94 \%$ & $1 \%$ & $1 \%$ & $40 \%$ \\
\hline $\mathrm{Graz}^{7}$ & GK & 192 & 1992-98 & 62 & & 12-14Gy & $98 \%$ & $1 \%$ & $1.5 \%$ & $62 \%$ \\
\hline Pittsburgh $^{5}$ & GK & 190 & 1992-97 & 30 & 2.7 & $13 \mathrm{~Gy}$ & $97 \%$ & $1 \%$ & $2.5 \%$ & $71 \%$ \\
\hline Tokyo $^{8}$ & GK & 138 & 1990-98 & 37 & 1.8 & 15.4 Gy & $91 \%$ & $6.5 \%$ & $25 \%$ & $58 \%$ \\
\hline Florida ${ }^{9}$ & Linac & 149 & 1988-98 & 36 & 4.8 & $14 \mathrm{~Gy}$ & $93 \%$ & $12 \%$ & $10 \%$ & NA \\
\hline This study & GK & 238 & $1996-99$ & 35 & 3.7 & $14.6 \mathrm{~Gy}$ & $92-97 \%$ & $1 \%$ & $1.5 \%$ & $75 \%$ \\
\hline
\end{tabular}

Comparisons are difficult to make because of differences in patient selection, and in data collection and analysis. Of note, the tumour control figures of $91-94 \%$ are based on descriptions of radiological control, whilst values of $97-98 \%$ reflect freedom from surgical resection. The complication rates of the Tokyo study report any trigeminal nerve dysfunction (the equivalent value in this study being $5 \%$ ), severe (at least House-Brackmann grade 5) facial palsy, and hearing preservation as less than a $20 \mathrm{~dB}$ change in the pure tone audiogram. Also of note, $89 \%$ of the patients in the Tokyo study had treatments planned on computed tomography. Auditory function was not assessed in the linear accelerator study.

GK, gamma knife; NA, not assessed.

been to reduce the dose to minimise complications. Given the good levels of tumour control currently achieved with a low complication rate, it seems unlikely that we should be increasing the dose with the aim of causing more tumour shrinkage, especially considering that while the odds ratio was 1.31, the lower limit of the confidence interval was 1.02 per 1 Gy increase in the marginal dose.

In counselling patients about treatment, it is important to consider the treatment options, which are those of observation, stereotactic irradiation, and surgery. Hitherto, most of the debate has concentrated on the relative roles of radiosurgery and microsurgery, and indeed this was specifically examined by a retrospective comparison of patients managed by the two modes in a single unit. ${ }^{17}$ This study suggested that radiosurgery caused less treatment associated morbidity, required shorter hospital stays, and allowed a faster return to independent functioning. Predictably the study was criticised for its retrospective nature and its length of follow up. Its results, however, are those we would expect based on our own experience and on our reading of the microsurgical literature. Even in the largest series and the most experienced hands, there is a mortality associated with surgery of $1 \%$, with a further $1 \%$ risk of hemiparesis or tetraparesis, and a cranial nerve morbidity and a functional hearing loss rate far in excess of that which we report here. ${ }^{16}{ }^{18}$ Furthermore, when patients' rather than surgeons' views are reported, the clinical experiences may be worse. ${ }^{19}$ Given these concerns, and that the treatments differ so much in what they entail for the patient, we do not believe that a prospective randomised study will ever be feasible, because patients will not want to be randomised.

One of the major limitations of radiosurgery is tumour size. In general in the gamma knife radiosurgical community there is a reluctance to treat tumours larger than $3-3.5 \mathrm{~cm}$ in diameter because of the perceived risk of damaging the brain stem. Currently we would regard surgery as being the preferred option for large tumours provided the patient is fit, as this will create space in the posterior fossa. The greater dilemma is if the patient is not fit, but has a large and growing tumour, in which case the options are between stereotactic radiotherapy and radiosurgery. Reviewing our results by tumour size, 17 patients were treated with neuromas of maximum diameter $3-3.5 \mathrm{~cm}$, one of whom subsequently underwent surgery; eight patients had lesions $3.5-4 \mathrm{~cm}$, six of which were controlled (one subsequently operated upon and one pending a surgical decision); and nine had lesions $4 \mathrm{~cm}$ or greater in diameter, two of which underwent surgery. While control rates of $75 \%$ are poor compared with the results of this series as a whole-and reflecting this we have been reluctant to treat large tumours-this may still be a useful strategy in patients who have no good surgical option. Obviously including such patients in a radiosurgery series will worsen the results, but this does not invalidate the approach as applied to an individual.

Concern has been expressed about the risk of exposing benign tumours to radiation and inducing malignant transformation. We are only aware of one patient in our department's total experience of treating 800 acoustic neuromas, with histological evidence of malignancy after radiosurgery. This was a patient with NF2 and rapid tumour growth both before and after radiosurgery, there being no evidence that the radiosurgery caused the atypical behaviour. ${ }^{20}$ The incidence of malignant transformation would appear to be very low. When counselling individual patients this risk pales into insignificance when compared with the combined risk of $2.2 \%$ of death or of serious neurological morbidity associated with open surgery. ${ }^{16}$

\section{CONCLUSIONS}

In a consecutive series of 234 tumours treated over a four year period, the tumour control rate was $92 \%$, only $3 \%$ of patients subsequently undergoing surgery. This compares favourably with recurrence rates seen after surgery. ${ }^{21}$ This is achieved with a $75 \%$ hearing preservation rate, and a complication rate for persisting facial and trigeminal neuropathies of $1-1.5 \%$. We believe that this success rate, with its low morbidity and minimally invasive nature, will make radiosurgery the treatment of choice for many patients with small and medium sized acoustic neuromas.

\section{ACKNOWLEDGEMENTS}

We would like to express our gratitude and debt to Mr David Forster, for his efforts in establishing the National Centre for Stereotactic Radiosurgery in Sheffield, and for his work in applying radiosurgery to the treatment of acoustic neuromas.

\section{Authors' affiliations \\ J G Rowe, M W R Radatz, L Walton, A Hampshire, S Seaman, \\ A A Kemeny, Department of Stereotactic Radiosurgery, Royal Hallamshire Hospital, Sheffield, UK}

Competing interests: none declared

\section{REFERENCES}

1 Rowe JG, Radatz MWR, Walton L, et al. Changing utilization of stereotactic radiosurgery: the Sheffield experience. Br J Neurosurg 2002;16:477-82.

2 Noren G, Greitz D, Hirsch A, et al. Gamma knife surgery in acoustic tumours. Acta Neurochir Suppl (Wien) 1993;58:104-7. 
3 Lundsford LD Kondziolka D, Flickinger JC, et al. Acoustic neuroma management: evolution and revolution. In: Alexander E, Kondziolka D, Lindquist C, et al, eds. Radiosurgery, vol 2. Basel: Karger, 1997:1-7.

4 Kondziolka D, Lunsford LD, McLaughlin MR, et al. Long term outcomes after radiosurgery for acoustic neuromas. N Engl J Med 1998;339:1426-33.

5 Flickinger JC, Kondziolka D, Niranjan A, et al. Results of acoustic neuroma radiosurgery: an analysis of 5 years experience using current methods. J Neurosurg 2001;94:1-6.

6 Prasad D, Steiner M, Steiner L. Gamma surgery for vestibular schwannoma. J Neurosurg 2000;92:745-59.

7 Unger F, Walch C, Haselberger K, et al. Radiosurgery of vestibular schwannomas: a minimally invasive alternative to microsurgery. Acto Neurochir (Wien) 1999;141:1281-5

8 Ito K, Shin M, Matsuzaki M, et al. Risk factors for neurological complications after acoustic neuroma radiosurgery: refinement from further experience. Int J Radiat Oncol Biol Phys 2000;48:75-80.

9 Foote KD, Friedman WA, Buatti JM, et al. Analysis of risk factors associated with radiosurgery for vestibular schwannoma. J Neurosurg 2001;95:440-9.

10 Forster DMC, Kemeny AA, Pathak A, et al. Radiosurgery: a minimally interventional alternative to microsurgery in the management of acoustic neuroma. Br J Neurosurg 1996;10:169-74.

11 Rowe JG, Radatz MWR, Walton L, et al. Clinical experience with gamma knife stereotactic radiosurgery in the management of vestibular schwannomas secondary to type 2 neurofibromatosis. I Neurol Neurosurg Psychiatry 2003;74:1288-1293.

12 Samii M, Matthies C, Tatagiba M. Management of vestibular schwannomas (acoustic neuromas): auditory and facial nerve function after resection of 120 vestibular schwannomas in patients with neurofibromatosis 2. Neurosurgery 1997:40:696-706

13 Gardner G, Robertson JH. Hearing preservation in unilateral acoustic neuroma surgery. Ann Otol Rhinol Laryngol 1988:97:55-66.

14 Ganz JC. Gamma knife surgery, a guide for referring physicians. New York: Springer-Verlag Wien, 1993.

15 House WF, Brackmann DE. Facial nerve grading system. Otolaryngol Head Neck Surg 1985;93:184-93.

16 Samii M, Matthies C. Management of 1000 vestibular schwannomas (acoustic neuromas): surgical management and results with an emphasis on complications and how to avoid them. Neurosurgery 1997;40:11-23.

17 Pollock BE, Lunsford LD, Kondziolka D, et al. Outcome analysis of acoustic neuroma management: a comparison of microsurgery and stereotactic radiosurgery. Neurosurgery 1995;36:215-29.

18 Samii M, Matthies C. Management of 1000 vestibular schwannomas (acoustic neuromas): hearing function in 1000 tumor resections. Neurosurgery 1997;40:248-62

19 Wiegand DA, Fickel V. Acoustic neuroma - the patient's perspective: subjective assessment of symptoms, diagnosis, therapy and outcome in 541 patients. Laryngoscope 1989;99:179-87.

20 Bari ME, Forster DMC, Kemeny AA, et al. Malignancy in a vestibular schwannoma. Report of a case with central neurofibromatosis treated by stereotactic radiosurgery and surgical excision with a review of the literature. Br J Neurosurg 2002;16:284-9.

21 Cerullo L, Grutsch JF, Heiferman K, et al. The preservation of hearing and facial nerve function in a consecutive series of unilateral vestibular nerve schwannoma surgical patients (acoustic neuroma). Surg Neurol 1993;39:485-93. 